\title{
COMPARATIVE STUDY BETWEEN THREE EXTRA-GLOTTIC AIRWAY DEVICES WITH GASTRIC ACCESS IN GENERAL SURGERY
}

\author{
By \\ Mohammed Mosleh Mohammed Mohammed Zabady, Talaat \\ Mohammed Abd El-Haleem, Anwar Mohamed Mostafa Al-Hassanin and \\ Nasr Abd El-Aziz Mohammed Saad
}
Department of Anesthesiology and Intensive Care, Faculty of Medicine, Al-Azhar University

Corresponding author: Mohammed Mosleh Zabady;

Mobile: 01066555895, E-mail: drmo_zabady@yahoo.com

\begin{abstract}
Background: Extraglottic airway devices (EGADs) - synonyms may be supraglottic airway devices (SADs, SGAs) or supra-laryngeal airways (SLA), are an integral part of modern anesthetic practice. These devices are inserted into the oral cavity after induction to anesthesia and help to provide patent airways during surgery.

Objective: To compare the efficacy of three extra-glottic airway devices with gastric access tube namely: Proseal LMA, Air-Q, and Baska Mask in providing an adequate airway seal for general surgery in paralyzed patients with apparent normal airways, receiving controlled ventilation.
\end{abstract}

Patients and Methods: This study was carried out in Al-Azhar University Hospitals, designed prospective, randomized, single-blinded study, included 90 adult male and female patients with ASA physical status class I or II, aged $18-44$ years who were scheduled to have elective surgeries under general anesthesia constituted the population of the present study. Inclusion criteria of this study obtained after approval of the Anesthesia Department's Research/Ethics Committee and written informed consents were obtained from the patients.

Results: As regard EGAD insertion, there were no cases of failed insertion of all airway devices. The Baska Mask was the easiest device to be inserted, while the PLMA was easier than Air Q. Both Baska Mask and PLMA showed a higher rate of insertion from first attempt than Air Q. The study showed that there was no need for repositioning or any manipulations of the device for optimization of ventilation in the Baska Mask group, while there was a need for optimizing the position in 6.7\% and 13.3\% in PLMA and Air Q groups, respectively. The duration of insertion in the Baska Mask group was the shortest among the three groups with significant difference compared with other two groups. The duration of insertion in PLMA group was shorter than Air Q group. Suprasternal notch test was done in both Baska Mask and PLMA groups only as the tip of NGT channel did not reach esophagus in the Air-Q group. There was a significant difference between PLMA and Baska Mask Groups ( $\mathrm{p}=0.00)$. The test was negative in 1 patient $(3.3 \%)$ in PMLA group in contrast to 2 patients in Baska Mask group (6.7\%). There was no major complication in all patients in all groups. There was neither vomiting nor hoarseness of voice in all groups. There was no displacement of any device in the Baska Mask group. In both Air Q and PLMA groups displacement occurred in (3.3\%) of devices. The devices that stained with bloody sputum were $(23.3 \%),(26.7 \%)$ and $(6.7 \%)$ of devices in PLMA, Air Q, and Baska Mask groups, respectively. The patients who complained of sore throat after recovery were $(16.7 \%)$, $(23.3 \%)$ and (6.7\%) in PLMA, Air Q, and Baska Mask groups, respectively.

Conclusion: Baska Mask was the easiest device to be inserted as it has the least insertion trials. PLMA was easier in insertion than the Air-Q as it has less insertion trials.Air-Q has the best glottic view through the FOB and higher seal pressure than Baska Mask. 
Keywords: PLMA, Air-Q intubating laryngeal airway, Bask Amask air way, General surgery.

\section{INTRODUCTION}

Extra-glottic airway devices (EGAD) are now widely used in Clinical Anaesthesia in General surgery. Some experts recommend using the devices with an incorporated additional channel for drainage or suctioning of gastric fluid in this instance (Chen et al., 2013).

The Proseal LMA (PLMA) (LMA North America, San Diego, CA) was introduced in 2000 as the first EGAD with two tubes for end-to-end contact with the respiratory and alimentary tracts (Frek et al., 2015). A drain tube in the PLMA separates the esophagus from the larynx. If the drainage tube is positioned correctly, it reduces the risk of aspiration if regurgitation occurs (Wong et al., 2012). A second cuff, behind the main body of the mask, increases contact with the posterior pharyngeal wall, increasing oropharyngeal leak pressure to an average of $25 \mathrm{~cm} \mathrm{H} 2 \mathrm{O}$ (Qamarul Hoda et al., 2017).

The Air-Q/Intubating Laryngeal Airway (ILA) was developed by Dr. Daniel Cook and introduced in 2004. The Air-Q/ILA (Cookgas LLC, St. Louis, MO, USA) is an extra-glottic airway device for use as a primary airway device or as an adjunct to tracheal intubation. The AirQ/ILA is available as a disposable or nondisposable device. It has an elliptical, inflatable, cuffed mask and a slightly curved airway tube with a detachable connector (Hernandez et al., 2012).

Baska Mask, designed by Australian anesthetist Kanag and MeenaBaska, is provided in a single use and multi-use versions. The Baska Mask obviates the need for orogastric tube and replaces this with a sump and two drains. The Baska Mask brings together features high seal pressure, gastric access part and bite block, which facilitate ventilation, provide air way protection and minimize air way obstruction respectively (Sharma et al., 2017).

The aim of the present study was to compare the efficacy of three extra-glottic airway devices with gastric access tube namely: Proseal LMA, Air-Q and Baska Mask in providing an adequate airway seal for general surgery in paralyzed patients with apparent normal airways, receiving controlled ventilation.

\section{PATIENTS AND METHODS}

After obtaining approval of the Anesthesia Department's Research/Ethics Committee and written informed consents obtained from all patients, 90 adult male and female patients with ASA physical status class I or II, aged $18-44$ years who were scheduled to have elective surgeries under general anesthesia constituted the population of the present study.

Patients were randomly divided into 3 equal groups according to EGAD used. Group I: ProSeal LMA (PLMA), Group II: (Air-Q), and Group III: Baska mask. The size of the EGAD was chosen in accordance to manufacturer's recommendations (El-ganzouri et al., 2011).

Pre-oxygenation was applied for $3 \mathrm{~min}$ using a facemask and oxygen $100 \%$. When the oxyhemoglobin saturation reached $100 \%$, and the expired oxygen concentration $(\mathrm{EtO} 2)$ reached above $80 \%$ 
anesthesia was induced by I.V. fentanyl $(1 \mu \mathrm{g} / \mathrm{kg})$ and propofol $(2 \mathrm{mg} / \mathrm{kg})$. Patient's ventilation was then assisted using bag and mask before giving atracurium (0.5 $\mathrm{mg} / \mathrm{kg}$ ) to facilitate EGAD insertion. Thirty seconds after drug administration, the patient was manually ventilated by facemask with $100 \%$ oxygen and sevoflurane (4\%).

The EGAD was inserted when the jaw became sufficiently slack and when TOF count became zero on the peripheral nerve stimulator assessed visually. Before placement, the EGA devices were tested for leaks and lubricated on the tip and posterior surface with water-soluble gel.

Airway seal pressure, grade of ease of EGAD insertion, number of attempts for EGAD insertion, duration of EGAD insertion, the ease of insertion of the EGAD, any maneuvers required to optimize positioning or ventilation, glottic view with the use of FOB, oxygenation quality, ease of gastric tube insertion Time to insertion of the gastric tube, hemodynamic response to EGAD insertion and complications, were assessed.
The calibration curves were obtained by plotting the absorbance readings (calculate the mean absorbance) of the standards (linear, y-axis) against the corresponding standard concentrations (logarithmic, $\mathrm{x}$-axis).

\section{Statistical Analysis:}

Sample size calculation was based on previous studies, and concluded that 30 patients for each subgroup were sufficient to give $\alpha=0.05$ with confidence interval $95 \%$ and actual power $80 \%$ and $\beta=0.2$, for airway seal pressure.

Data was collected, tabulated, coded then analyzed using SPSS $^{\circledR}$ computer software version 15 for Windows. Firstly, numerical variables were presented as mean \pm standard deviation whenever appropriate. On the other hand, categorical variables were presented as number of cases (percent). For parametric data, one-way ANOVA was used to compare between the three groups. Tukey's post-hoc test was used for pairwise comparisons when ANOVA test is significant. The significance level was set at $\mathrm{P} \leq 0.05$. 


\section{RESULTS}

There were no statistically significant differences between the 3 groups of the study as regards their demographic data (age, height, weight, BMI, El-Ganzouri
Risk Index score) (Table 2) and Types of general surgeries were comparable between the three groups (Table 1).

Table (1): Patient characteristics

\begin{tabular}{|c|c|c|c|c|c|}
\hline \multirow{2}{*}{\multicolumn{2}{|c|}{$\begin{array}{ll}\text { Parameters } & \text { Groups } \\
\end{array}$}} & PLMA & \multirow{2}{*}{ Air Q $(n=30)$} & \multirow{2}{*}{$\begin{array}{l}\text { Baska Mask } \\
\quad(n=30)\end{array}$} & \multirow{2}{*}{$P$ value } \\
\hline & & $(n=30)$ & & & \\
\hline \multirow{3}{*}{ Age (years) } & Range & $18-35$ & $18-41$ & $18-44$ & \multirow{3}{*}{$>0.05$} \\
\hline & \multirow{2}{*}{ Mean \pm SD } & \multirow{2}{*}{$26.30 \pm 4.58$} & \multirow{2}{*}{$28.72 \pm 6.648$} & $28.40 \pm$ & \\
\hline & & & & 6.089 & \\
\hline Weight (kg) & Mean \pm SD & $72.40 \pm 4.399$ & $72.80 \pm 3.38$ & $72.53 \pm 4.321$ & $>0.05$ \\
\hline Height (m) & Mean \pm SD & $1.67 \pm 0.037$ & $1.68 \pm 0.057$ & $1.67 \pm 0.39$ & $>0.05$ \\
\hline BMI(kg/m2) & Mean \pm SD & $26.10 \pm 1.373$ & $26.03 \pm 1.033$ & $25.20 \pm 1.448$ & $>0.05$ \\
\hline \multirow{4}{*}{$\begin{array}{l}\text { El-Ganzouri } \\
\text { Score }\end{array}$} & 0 & $13(43.3 \%)$ & $6(20 \%)$ & $9(30 \%)$ & \multirow{4}{*}{$>0.05$} \\
\hline & 1 & $10(33.3 \%)$ & $14(46.7 \%)$ & $15(50 \%)$ & \\
\hline & 2 & $5(16.7 \%)$ & $8(26.7 \%)$ & $5(16.7 \%)$ & \\
\hline & 3 & $2(6.7 \%)$ & $2(6.7 \%)$ & $1(3.3 \%)$ & \\
\hline
\end{tabular}

Data presented as (mean \pm SD) and $\mathrm{n}(\%)$.

There was no failure in insertion of any device in all groups. Difficulty in insertion was encountered in 5/30 (16.6\%) of Air-Q group in comparison to PLMA and Baska
Mask groups which showed difficulty in $2 / 30(6.7 \%)$ and $1 / 30(3.3 \%)$ respectively (Table 2).

\section{Table (2): Types of surgery}

\begin{tabular}{|c|c|c|c|c|}
\hline Types of surgery & $\begin{array}{c}\text { PLMA } \\
(\mathrm{n}=30)\end{array}$ & Air Q $(\mathrm{n}=30)$ & $\begin{array}{c}\text { Baska Mask } \\
(\mathrm{n}=30)\end{array}$ & TOTAL \\
\hline Inguinal Hernia & $19(63.3 \%)$ & $18(60 \%)$ & $20(66.7 \%)$ & $57(63.33 \%)$ \\
\hline Umbilical Hernia & $8(26.7 \%)$ & $9(30 \%)$ & $5(16.6 \%)$ & $\begin{array}{c}22 \\
(24.22 \%)\end{array}$ \\
\hline Abdominal Lipoma & $2(6.7 \%)$ & $1(3.3 \%)$ & $2(6.7 \%)$ & $5(5.55 \%)$ \\
\hline Varicocele & $1(3.3 \%)$ & $2(6.7 \%)$ & $2(6.7 \%)$ & $5(5.55 \%)$ \\
\hline Exploration & - & - & $1(3.3 \%)$ & $1(1.11 \%)$ \\
\hline P Value & & $>0.05$ & & \\
\hline
\end{tabular}

Data presented as n (\%)

There was no failure in insertion of any device in all groups. Difficulty in insertion was encountered in 5/30 (16.6\%) of Air-Q group in comparison to PLMA and Baska
Mask groups which showed difficulty in $2 / 30(6.7 \%)$ and $1 / 30(3.3 \%)$ respectively (Table 3). 
Table (3): Difficulty of EGAD insertion

\begin{tabular}{|c|c|c|c|c|}
\hline Parameters & PLMA & Air Q & Baska Mask & \multirow{2}{*}{ P value } \\
\cline { 1 - 4 } Easy & $28(93.3 \%)$ & $25(83.3 \%)$ & $29(96.6 \%)$ & \multirow{2}{*}{$>0.05$} \\
\cline { 1 - 4 } Difficult & $2(6.7 \%)$ & $5(16.6 \%)$ & $1(3.3 \%)$ & \\
\hline Impossible & - & - & - & \\
\hline
\end{tabular}

Successful insertion from the first attempt was 28/30 (93.7\%) in PLMA Mask group where it was $26 / 30(86.7 \%)$ and 29/30 (96.7\%), in Air Q groups and Baska group, respectively. From the second trial, successful insertion was 2/30
(6.7\%) in PLMA Mask group while it was $3 / 30(10 \%)$ and $1 / 30(3.3 \%)$ in Air Q and Baska groups, respectively. Only one patient in the Air-Q group required insertion of the device from the third attempt 1/30 (3.3\%) (Table 4).

Table (4): Number of trials of EGAD insertion

\begin{tabular}{|c|c|c|c|c|}
\hline Parameters & $\begin{array}{c}\text { PLMA } \\
(\mathrm{n}=30)\end{array}$ & $\begin{array}{c}\text { Air Q } \\
(\mathrm{n}=30)\end{array}$ & $\begin{array}{c}\text { Baska Mask } \\
(\mathrm{n}=30)\end{array}$ & P value \\
\cline { 1 - 4 } 1st trial & $28(93.3 \%)$ & $26(86.7 \%)$ & $29(96.7 \%)$ & \multirow{2}{*}{$>0.05$} \\
\hline 2nd trial & $2(6.7 \%)$ & $3(10 \%)$ & $1(3.3 \%)$ & \\
\hline 3rd trial & 0 & $1(3.3 \%)$ & 0 & \\
\hline
\end{tabular}

Data presented as n (\%).

There was no need for optimization of position or ventilation in Baska Mask group. While both PLMA and Air Q groups required positioning adjustment in $2 / 30(6.7 \%)$ and $4 / 30(13.3 \%)$ patients, respectively (Table 5).

Table (5): Maneuvers required to optimize positioning of EGAD

\begin{tabular}{|c|c|c|c|}
\hline $\begin{array}{ll}\text { Parameters } & \text { Groups } \\
\end{array}$ & $\begin{array}{l}\text { PLMA } \\
(\mathrm{n}=30)\end{array}$ & $\begin{array}{c}\text { Baska Mask } \\
(\mathrm{n}=30)\end{array}$ & $P$ value \\
\hline Yes & $2(6.7 \%)$ & $4(13.3 \%)$ & \multirow{2}{*}{$>0.05$} \\
\hline No & $28(93.3 \%)$ & $26(86.7 \%)$ & \\
\hline
\end{tabular}

The duration of insertion in Baska Mask group was the shortest among the three studied groups $(8.97 \pm 1.299 \mathrm{sec})$ with significant difference compared to the other groups. Insertion duration in
PLMA group was significantly ( $\mathrm{p}=$ $<0.001)$ shorter than that in Air Q group $(14.43 \pm 1.794 \mathrm{sec}$ and $17.63 \pm 1.938 \mathrm{sec})$ respectively (Table 6).

Table (6): Duration of insertion of EGAD

\begin{tabular}{|c|c|c|c|c|}
\hline Groups & $\begin{array}{c}\text { PLMA } \\
(\mathrm{n}=30)\end{array}$ & $\begin{array}{c}\text { Air Q } \\
(\mathrm{n}=30)\end{array}$ & $\begin{array}{c}\text { Baska Mask } \\
(\mathrm{n}=30)\end{array}$ & P value \\
\hline $\begin{array}{c}\text { Durameters } \\
\text { insertion of EGAD }(\mathrm{sec})\end{array}$ & $14.43 \pm 1.794$ & $17.63 \pm 1.938$ & $8.97 \pm 1.299$ & $<0.001$ \\
\hline
\end{tabular}

Data were presented as Mean (SD) values, results of one-way ANOVA and Tukey's tests.

Different superscripts in the same row were statistically significantly different according to Tukey's test. 
There was no significant difference between the 3 groups when MAP recorded at baseline, 1, 3 and 5 minutes after EGAD placement. At baseline MAP was (94.23 \pm 2.63$),(94.24 \pm 2.61)$ and $(95.86$ \pm 7.83) in PLMA, Air Q, and Basks groups, respectively. At $1 \mathrm{st} \mathrm{min}$ after induction, it was $(95.48 \pm 2.55),(95.3 \pm$ 2.49) and (94.96 \pm 2.96$)$ in in PLMA, Air
Q, and Basks groups, respectively. At 2nd min, it was $(95.89 \pm 2.57),(95.65 \pm 2.56)$ and $(94.48 \pm 3.23)$ in in PLMA, Air Q, and Basks groups, respectively. At 3rd $\min$, it was $(94.13 \pm 2.86),(94.2 \pm 2.57)$ and $(93.74 \pm 2.96)$ in in PLMA, Air Q, and Basks groups, respectively as shown in (Table 7).

Table (7): Mean blood pressure difference between the three groups

Date presented as mean $\pm \mathrm{SD}$

\begin{tabular}{|c|c|c|c|c|}
\hline Groups & $\begin{array}{c}\text { PLMA } \\
(\mathrm{n}=30)\end{array}$ & $\begin{array}{c}\text { Air Q } \\
(\mathrm{n}=30)\end{array}$ & $\begin{array}{c}\text { Baska Mask } \\
(\mathrm{n}=30)\end{array}$ & P value \\
\hline Parameters & $94.23 \pm 2.63$ & $94.24 \pm 2.61$ & $95.86 \pm 7.83$ & $>0.05$ \\
\hline Baseline & $95.48 \pm 2.55$ & $95.3 \pm 2.49$ & $94.96 \pm 2.96$ & $>0.05$ \\
\hline 1st min & $95.89 \pm 2.57$ & $95.65 \pm 2.56$ & $94.48 \pm 3.23$ & $>0.05$ \\
\hline 3rd min & $94.13 \pm 2.86$ & $94.2 \pm 2.57$ & $93.74 \pm 2.96$ & $>0.05$ \\
\hline
\end{tabular}

Full view of the vocal cords (score 1) was seen in 24 patients (80\%) in PLMA group and in 25 patients in Air Q Group $(83.4 \%)$ and in 20 patients $(66.6 \%)$ in Baska Mask group. Partial view of the vocal cords including the arytenoids (score 2) was seen in 4 patients $(13.3 \%$ ) in
PLMA and Air Q groups; and in 7 Patients $(23.3 \%)$ in Air Q group. View of the epiglottis only (score 3 ) was seen in 2 patients $(6.7 \%), 1$ patient $(3.3 \%)$ and 3 patients $(10 \%)$ in PLMA, Air Q, and Baska groups, respectively (Table 8).

Table (8): Glottic view with the use of FBO

\begin{tabular}{|c|c|c|c|c|}
\hline Parameters & $\begin{array}{c}\text { PLMA } \\
(\mathrm{n}=30)\end{array}$ & $\begin{array}{c}\text { Air Q } \\
(\mathrm{n}=30)\end{array}$ & $\begin{array}{c}\text { Baska Mask } \\
(\mathrm{n}=30)\end{array}$ & P value \\
\cline { 1 - 4 } Score 1 & $24(80 \%)$ & $25(83.4 \%)$ & $20(66.6 \%)$ & \multirow{2}{*}{$>0.05$} \\
\cline { 1 - 4 } Score 2 & $4(13.3 \%)$ & $4(13.3 \%)$ & $7(23.3 \%)$ & \\
\hline Score 3 & $2(6.7 \%)$ & $1(3.3 \%)$ & $3(10 \%)$ & \\
\hline
\end{tabular}

Data presented as N (\%)

Airway seal pressure showed a significant difference between the three groups. The highest seal pressure was recorded in Air Q group (29.79 \pm 2.49$)$
mmHg followed by PLMA group $(29.39 \pm$ 1.96) and the lowest seal pressure was recorded in Baska Mask group (27.19 \pm 1.90) (Table 9).

Table (9): Airway Seal Pressure

\begin{tabular}{|c|c|c|c|c|}
\hline Groups & $\begin{array}{c}\text { PLMA } \\
(\mathrm{n}=30)\end{array}$ & $\begin{array}{c}\text { Air Q } \\
(\mathrm{n}=30)\end{array}$ & $\begin{array}{c}\text { Baska Mask } \\
(\mathrm{n}=30)\end{array}$ & P value \\
\hline Parameters & $29.39 \pm 1.96$ & $29.79 \pm 2.49$ & $27.19 \pm 1.90$ & 0.001 \\
\hline
\end{tabular}

Data are presented as Mean \pm SD values, results of one-way ANOVA and Tukey's tests.

Significant at $\mathrm{P} \leq 0.05$, statistically significantly different according to Tukey's test. 
There was no failure in insertion of NGT in all groups. Insertion was easy in 28/30 (93.3\%) in PLMA group, 26/30 $(86.7 \%)$ in Air Q group and in 29/30
(96.7\%) in Baska Mask group. It was difficult in 2/30 (6.7\%) in PLMA group, $4 / 30(13.3 \%)$ in Air Q group and in 1/30 (3.3\%) in Baska Mask group (Table 10).

Table (10): Grade of difficulty of NGT insertion

\begin{tabular}{|c|c|c|c|c|}
\hline Parameters $\quad$ Groups & $\begin{array}{l}\text { PLMA } \\
(\mathrm{n}=30)\end{array}$ & $\begin{array}{l}\text { Air Q } \\
(\mathrm{n}=30)\end{array}$ & $\begin{array}{c}\text { Baska Mask } \\
(\mathrm{n}=30)\end{array}$ & $P$ value \\
\hline Easy & $28(93.3 \%)$ & $26(86.7 \%)$ & $29(96.7 \%)$ & \multirow{3}{*}{$>0.05$} \\
\hline Difficult & $2(6.7 \%)$ & $4(13.3 \%)$ & $1(3.3 \%)$ & \\
\hline Impossible & - & - & - & \\
\hline
\end{tabular}

Data presented as N (\%)

Successful NGT insertion from the first attempt was recorded in 28/30 (93.3\%) of devices in PLMA group and in 26/30 $(86.7 \%)$ of devices inair Q group and in 29/30 (96.7\%) of devices in Baska Mask group. Second attempt was required in $2 / 30(6.7 \%)$ of devices in PLMA group and in $4 / 30(13.3 \%)$ of devices in Air Q group and in $1 / 30(3.3 \%)$ of devices in Baska Mask group (Table 11).

Table (11): Number of attempts of NGT insertion

\begin{tabular}{|c|c|c|c|c|}
\hline Parameters & $\begin{array}{c}\text { PLMA } \\
(\mathrm{n}=30)\end{array}$ & $\begin{array}{c}\text { Air Q } \\
(\mathrm{n}=30)\end{array}$ & $\begin{array}{c}\text { Baska Mask } \\
(\mathrm{n}=30)\end{array}$ & P value \\
\cline { 1 - 4 } $1^{\text {st }}$ Attempt & $28(93.3 \%)$ & $26(86.7 \%)$ & $29(96.7 \%)$ & \multirow{2}{*}{$>0.05$} \\
\hline $2^{\text {nd }}$ Attempt & $2(6.7 \%)$ & $4(13.3 \%)$ & $1(3.3 \%)$ & \\
\hline
\end{tabular}

Data presented as N (\%)

Stomach placement (positive test) was encountered with all devices in Baska mask and PLMA groups. Negative test was recorded in $5 / 30(16.7 \%)$ of cases in Air Q group (Table 12).

Table (12): Confirmation of position of tip of NGT

\begin{tabular}{|c|c|c|c|c|}
\hline Groups & $\begin{array}{c}\text { PLMA } \\
(\mathrm{n}=30)\end{array}$ & $\begin{array}{c}\text { Air Q } \\
(\mathrm{n}=30)\end{array}$ & $\begin{array}{c}\text { Baska Mask } \\
(\mathrm{n}=30)\end{array}$ & P value \\
\cline { 1 - 4 } Parameters & $30(100 \%)$ & $30(100 \%)$ & $25(83.3 \%)$ & \multirow{2}{*}{0.005} \\
\hline Positive & 0 & 0 & $5(16.7 \%)$ & \\
\hline
\end{tabular}

Data presented as N (\%), result of Chi-Square Tests.

Positive test $=$ correct stomach placement Oxygenation

Oxygenation quality: Oxygen desaturation did not occur at any time during the procedure in all devices.

Complications: There was no major complication in all patients in all groups. However, the following problems have been encountered.

Displacement of device: There was no displacement of any device in Baska Mask group. In both Air Q and PLMA groups displacement was encountered in $1 / 30$ $(3.3 \%)$ of devices.

Obstruction: There was no obstruction of any device in both Baska Mask and PLMA groups. In Air Q group obstruction was encountered in $2 / 30 \quad(6.7 \%)$ of devices. 
Vomiting: There was no vomiting noticed with any device in all groups.

Blood tinged sputum on the device: Bloody stained secretions were found on $7 / 30$ (23.3\%), 8/30 (26.7\%) and 2/30 $(6.7 \%)$ of devices in PLMA, Air Q, and Baska Mask groups, respectively.
Sore throat: Patients who complained from sore throat after recovery were $5 / 30$ (16.7\%), $7 / 30(23.3 \%)$ and $2 / 30(6.7 \%)$ in PLMA, Air Q, and Baska Mask groups, respectively.

Hoarseness of voice: Hoarseness of voice was not noticed with any device in all groups (Table 13).

Table (13): Complications

\begin{tabular}{|c|c|c|c|c|}
\hline Groups & $\begin{array}{c}\text { PLMA } \\
(\mathrm{n}=30)\end{array}$ & $\begin{array}{c}\text { Air Q } \\
(\mathrm{n}=30)\end{array}$ & $\begin{array}{c}\text { Baska Mask } \\
(\mathrm{n}=30)\end{array}$ & P value \\
\hline Displacement & 0 & $1(3.3 \%)$ & $1(3.3 \%)$ & $>0.05$ \\
\hline Obstruction & 0 & 0 & $2(6.7 \%)$ & $>0.05$ \\
\hline Vomiting & 0 & 0 & 0 & $>0.05$ \\
\hline Blood tinged sputum & $7(23.3 \%)$ & $8(26.7 \%)$ & $2(6.7 \%)$ & $>0.05$ \\
\hline Sore throat & $5(16.7 \%)$ & $7(23.3 \%)$ & $2(6.7 \%)$ & $>0.05$ \\
\hline Hoarseness of voice & 0 & 0 & 0 & $>0.05$ \\
\hline
\end{tabular}

a: No statistics were computed because it is a constant.

\section{DISCUSSION}

As regard the ease of insertion of EGAD, there were no cases of failed insertion of all airway devices i.e. $100 \%$ success rate in all groups. The Baska Mask was the easiest device to be inserted while the PLMA was easier than Air Q (Al-rawahi et al., 2013).

As regard the number of insertion attempts, both Baska Maskand PLMA showed a higher rate of insertion from first attempt than Air Q. The percentage of successful insertion from the first attempt in Baska Mask group was (96.7\%) in comparison with PLMA and Air Q groups that were $(93.3 \%)$ and $(86.7 \%)$, respectively (Galgon et al., 2011 and $\mathrm{Al}$ rawahi et al., 2013).

In the Baska Mask group, there was no need for repositioning or any manipulations of the device for optimization of ventilation. As regard the other two groups, there was a need for optimizing the position in $13.3 \%$ and $6.7 \%$ in PLMA and Air Q groups, respectively.

The duration of insertion in the Baska Mask group was the shortest among the three groups. The duration of insertion in PLMA group was shorter than Air Q group (Galgon et al., 2011 and Dhanasekaran et al., 2019).

Suprasternal notch test was done in both Baska Mask and PLMA groups only as the tip of NGT channel did not reach esophagus in Air Q group.

Changes in hemodynamic parameters were noted at base line (one minute before induction of anesthesia) and at 1, 3, 5 minutes after device placement. As regard to pulse rate changes, there was no significant difference between the three groups at base line $(75.43 \pm 3.28),(73.86$ $\pm 3.50)$ and $(75.32 \pm 3.80)$ in in PLMA, Air Q, and Baska groups, respectively (Attarde et al., 2016). 
As regard to systolic blood pressure, there was no significant difference between the 3 groups when SBP was recorded at baseline, 1, 3 and 5 minutes after EGAD placement. Diastolic blood pressure showed also no significant difference between the 3 groups when it measured at baseline, 1, 3 and 5 minutes after EGAD placement. As regard to mean arterial blood pressure (MAP), there was no significant difference between the 3 groups when MAP recorded at baseline, 1 , 3 and 5 minutes after EGAD placement (Kachakayala et al., 2019).

Hemodynamic changes due to pressor response on EGAD insertion are less in Baska Mask than PLMA, Air Q and other cuffed EGADs which may be induced by the passage of the LMA through the oral and pharyngeal spaces, and pressure may be produced in the larynx and the pharynx by the inflated cuff and the dome of the LMA (Jindal et al., 2019).

As regard the glottic view by fiberoptic bronchoscope, the Air Q was the best device in showing the full view of vocal cords (score 1). Full view of the vocal cords (score 1) was seen in $80 \%$ in PLMA group, $83.4 \%$ in patients in Air Q Group, and $66.6 \%$ in Baska Mask group. Partial view of the vocal cords including the arytenoids (score 2 ) was seen in $13.3 \%$ in both PLMA and Air Q groups; and in $23.3 \%$ in Air $Q$ group. View of the epiglottis only (score 3 ) was seen in $6.7 \%$, $3.3 \%$ and $10 \%$ in PLMA, Air Q, and Baska groups, respectively. One of the most important parameters to be compared between the three devices was the airway seal pressure which was almost similar in both Air Q and PLMA $29.79 \pm$ 2.49 and $29.39 \pm 1.96) \mathrm{mmHg}$, respectively. Both had ASP more than Baska Mask which had seal pressure of $27.19 \pm 1.90 \mathrm{mmHg}$ (Galgon et al., 2011).

NGT insertion through the gastric access was successful in all groups. Success of insertion from the first attempt was $93.3 \%$ in PLMA group, $86.7 \%$ in Air Q group and $96.7 \%$ in Baska Mask group. All NGTs in Baska Mask and PLMA groups were confirmed in the stomach. In the Air Q group (16.7\%) had negative test. This may be due to the design of Air Q as the gastric access dose not reaches the tip of the device compared to the other two devices where the access reaches the tip of the cuff of the device. As regard oxygenation quality during procedure, the oxygen saturation did not affected at any time in the procedure in all devices. There was no major complication in all patients in all groups. There was neither vomiting nor hoarseness of voice in all groups (Kachakayala et al., 2019).

There was no displacement of any device in the Baska Mask group. In both Air $\mathrm{Q}$ and PLMA groups displacement occurred in $1 / 30(3.3 \%)$ of devices. The devices that stained with bloody sputum were 7/30 (23.3\%), 8/30 (26.7\%) and 2/30 $(6.7 \%)$ in PLMA, Air Q groups, and Baska Mask, respectively. The number of patients who complained of sore throat after recovery were $16.7 \%, 23.3 \%$, and 6.7\% in PLMA, Air Q groups, and Baska Mask groups, respectively (Garpagalakshmi, 2019).

\section{CONCLUSION}

Baska Mask was the easiest device to be inserted as it has the least insertion trials, the shortest duration of insertion with no need for manipulations of the device for optimization of ventilation as 
well as it has the least effect on hemodynamics. It has the least complications either intraoperative or postoperative. However, the Baska Mask has the lowest seal pressure and the least FOB view score among the three studied groups.

PLMA was easier in insertion than the Air-Q as it has less insertion trials, less need for manipulation for optimization of ventilation and shorter duration of insertion as well as easier NGT insertion. Also, it has less effect on hemodynamics with less complication either intraoperative or postoperative. Seal pressure is almost equal to that of Air-Q. It has less FOB view score than that of the Air-Q.

Air-Q has the best glottic view through the FOB, higher seal pressure than Baska Mask but with greater effect on hemodynamics and more complications than other studied devices.

\section{REFERENCES}

1. Al-Rawahi S, Aziz H, Malik A, Khan $R$ and Kaul N. (2013): $A$ comparative analysis of the Baska ${ }^{\circledR}$ Mask vs . Proseal @ laryngeal mask for general anesthesia with IPPV. Anaesthesia, Pain and Intensive Care, 17(3):233-236.

2. Attarde, V. B., Kotekar, N. and Shetty, S. M. (2016): Air-Q intubating laryngeal airway: A study of the second generation supraglottic airway device. Indian journal of anaesthesia. Medknow Publications \& Media Pvt Ltd, 60(5), pp. 343-348.
3. Chen X, Jiao J, Cong X, Liu L and Wu X. (2013): A Comparison of the Performance of the I-gel ${ }^{\mathrm{TM}}$ vs. the LMA-S ${ }^{\text {TM}}$ during Anesthesia: A Meta-Analysis of Randomized Controlled Trials. PLOS One, 12: 36-45.

4. Dhanasekaran R, Mehta $G$ and Parameswari A. (2019): A Prospective Randomized Comparative Study between Baska Mask, Proseal LMA and I Gel during Positive Pressure Ventilation in Laparoscopic Cholecystectomy. JARSS, 27(2): 106-111.

5. El-Ganzouri AF, Marzouk S, Abdelalem $\mathbf{N}$ and Yousef $M$. (2011): Blind versus fiberoptic laryngoscopy intubation through air Q laryngeal mask airway. Egyptian Journal of Anaesthesia, 27(4): 213-218.

6. Frerk C, Mitchell VS, McNarry AF, Mendonca C, Bhagrath $\mathbf{R}$, Patel AA and Ahmad I. (2015): Difficult Airway Society 2015 guidelines for management of unanticipated difficult intubation in adults. British Journal of Anaesthesia, 115(6): 827-848.

7. Galgon RE, Schroeder KM, Han $S$, Andrei $A$ and Joffe AM. (2011): The air-Q $\left({ }^{\circledR}\right)$ intubating laryngeal airway vs the LMAProSeal(TM): a prospective, randomised trial of airway seal 
pressure. Anaesthesia, 66(12): 1093- 1100.

8. Garpagalakshmi S. (2019): A Comparative Study of Baska Mask and Proseal Laryngeal Mask for General Anaesthesia with Intermittent Positive Pressure Ventilation. JARSS, 18: 38-47.

9. Hernandez MR, Klock PA, Ovassapian A. (2012): Evolution of the extraglottic airway: a review of its history, applications, and practical tips for success. Anesth Analg., 114 (2): 349-368.

10. Jindal P, Rizvi AA, Khurana G and Sharma JP. (2019): Safety and efficacy of insertion of supraglottic devices in anaesthetised patients by first-time users. Southern African Journal of Anaesthesia and Analgesia, 16(4): 23-26.

11. Kachakayala RK, Bhatia P, Singh $S$ and Dwivedi D. (2019): A comparative study of supraglottic airway devices Baska mask and ProSeal-laryngeal mask airway in short gynaecological procedures. International Journal of Research in Medical Sciences, 8(1): 62-71.

12. Qamarul HM, Samad $K$ and Ullah H. (2017): Proseal versus Classic laryngeal mask airway (LMA) for positive pressure ventilation in adult patients undergoing elective surgery. Cochrane Database of Systematic Reviews, 3: 16-24.

13. Sharma B, Sahai $\mathrm{C}$ and Sood J. (2017): Extraglottic airway devices: technology update', Medical devices (Auckland, N.Z.). Dove Medical Press, 10: 189-205.

14. Wong DT, Yang JJ and Jagannathan N. (2012): Brief review: the LMA Supreme ${ }^{\mathrm{TM}}$ supraglottic airway. Canadian Journal of Anesthesia, 59(5): 483493. 


\section{در اسة مقارنة بين ثثلاثة مدر ات هو ائية خار ج الحنجرة وذو مدخل للمعدة في الجر احة العامه}

محمد مصلح محمد محمد زبادي، طلعت محمدعبدالحليم، أنورمحمد مصطفي الحسنين، نصر عبد العزيز محمد سعد

قسم التخدير والرعاية المركزة، كلية الطب، جامعة الأزهر

\section{E-mail: drmo_zabady@yahoo.com}

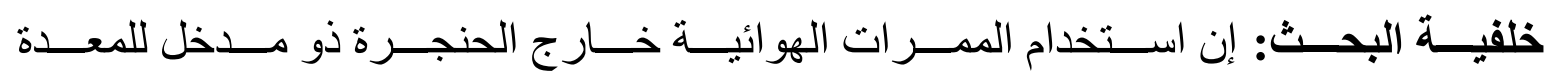

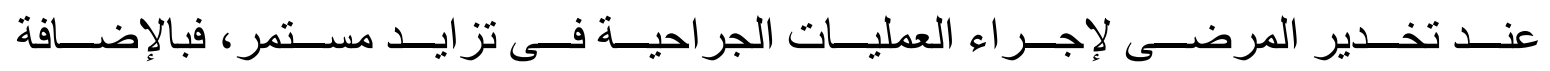

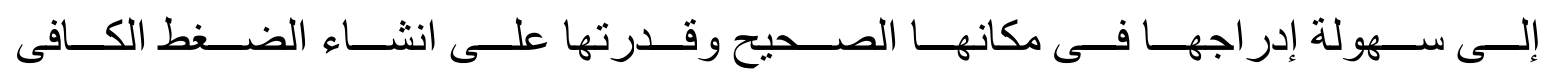

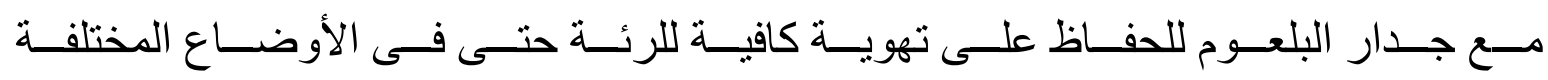

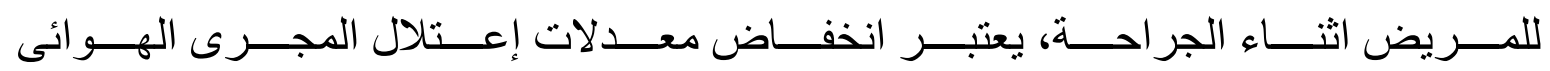

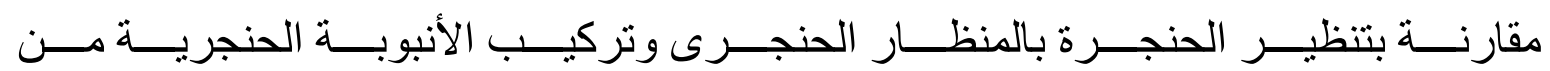
أفضل مميزات الممر ات الهو ائية خارج الحنجرة.

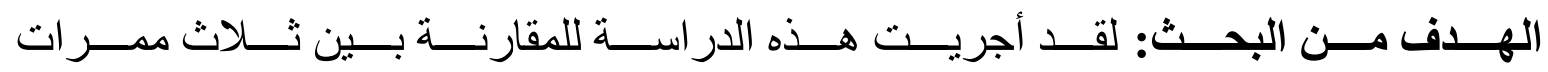

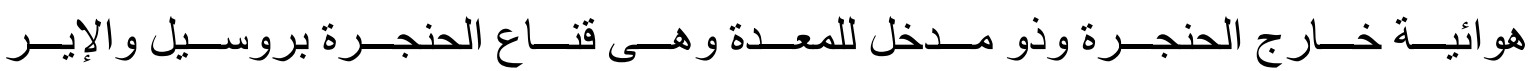
كيو و الباسكا ماسك فى العمليات الجر احية.

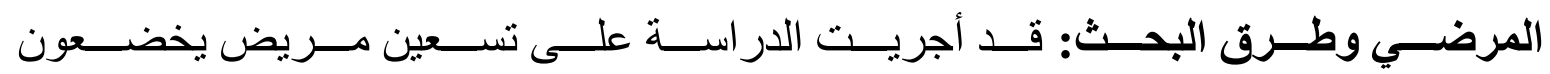

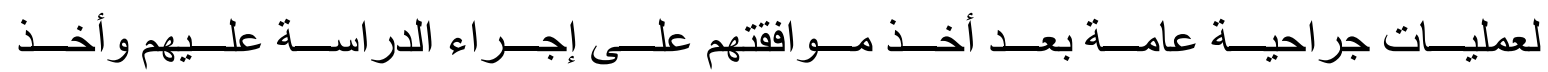

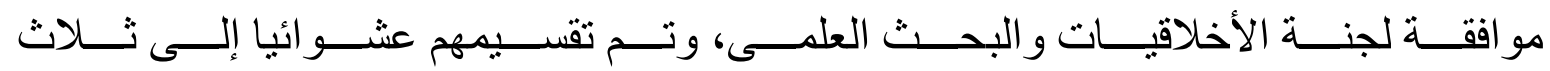

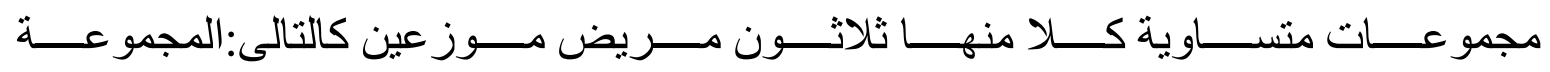

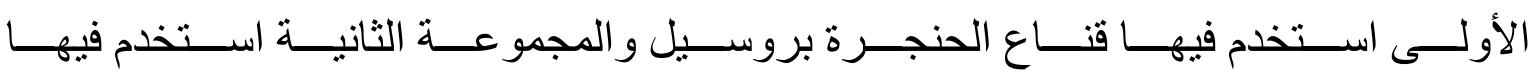
الإير كيو و المجموعة الثالثة استخدم فيها الباسكا ماسك كممر ات هو ائية.

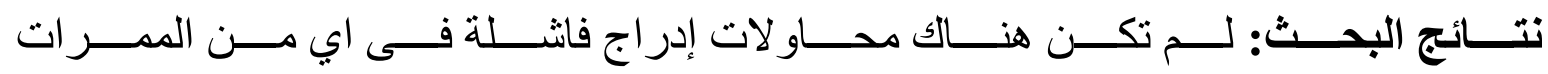

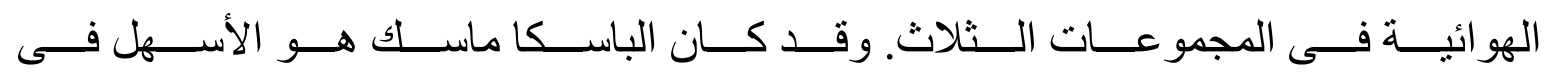




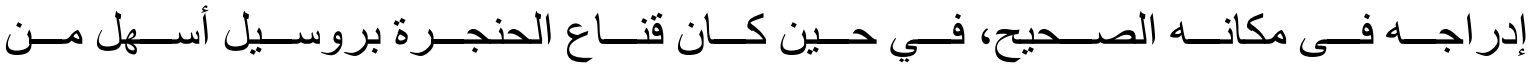

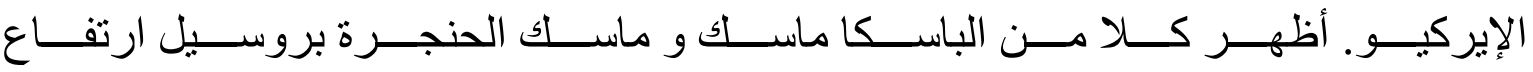

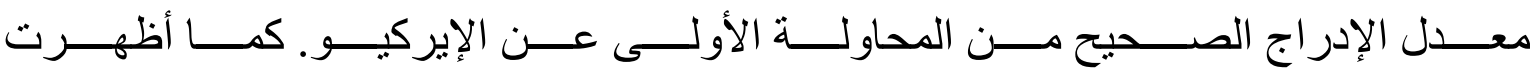

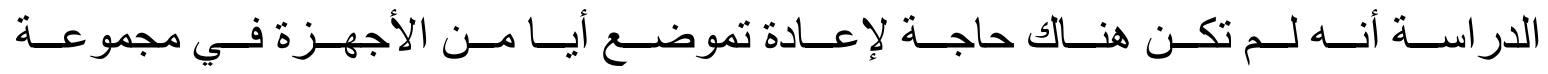

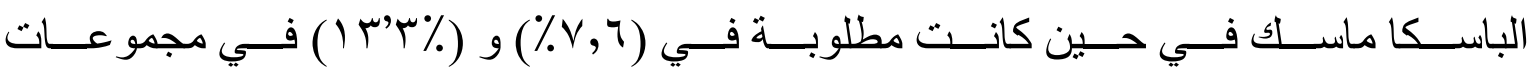

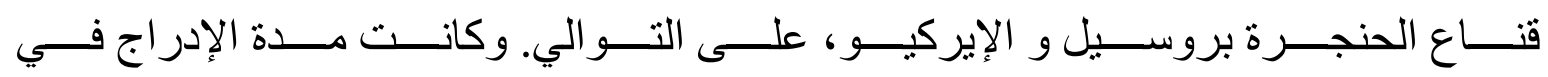

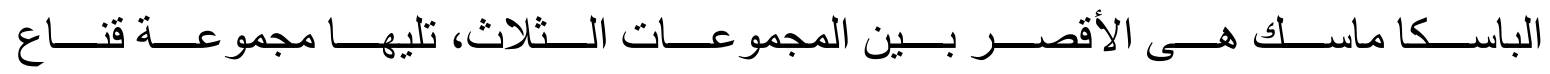

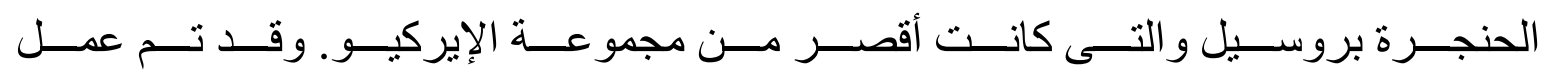

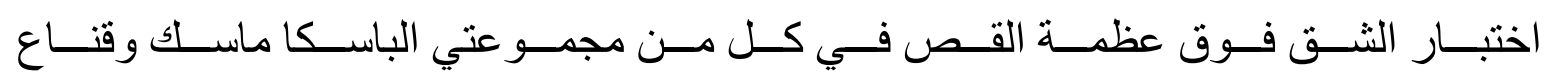

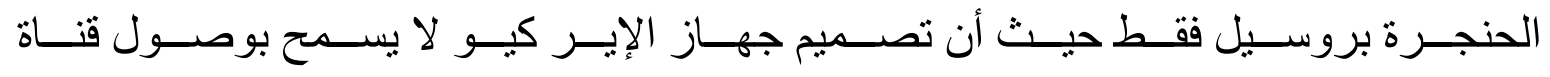

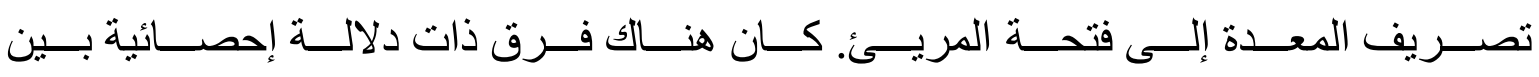

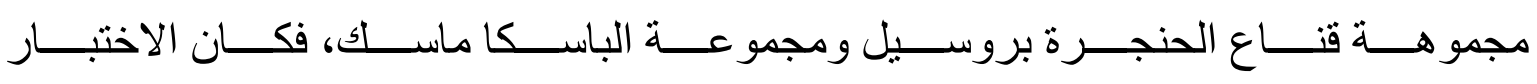

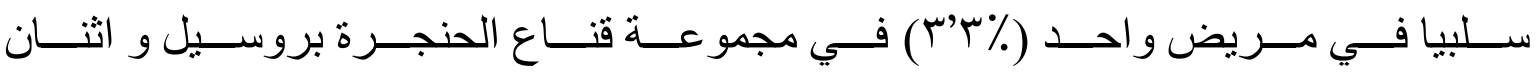

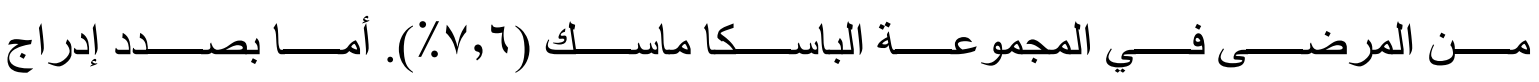

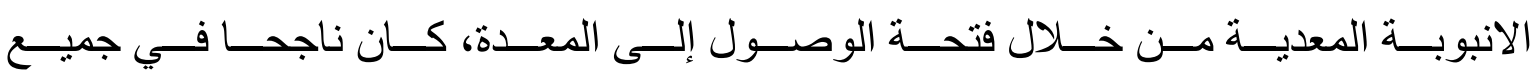

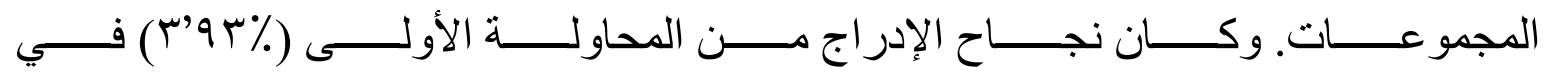

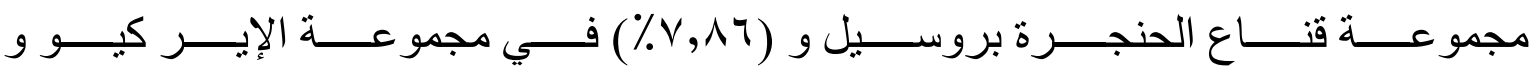

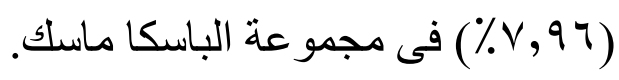

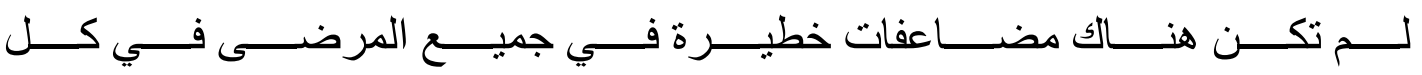

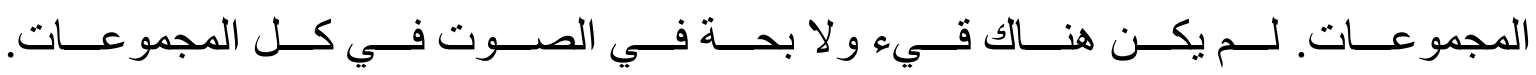

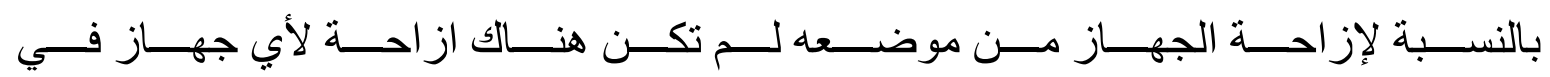

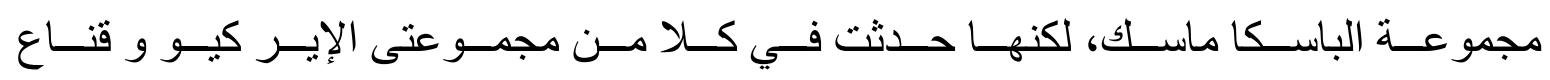

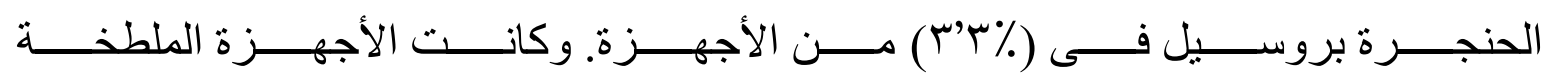

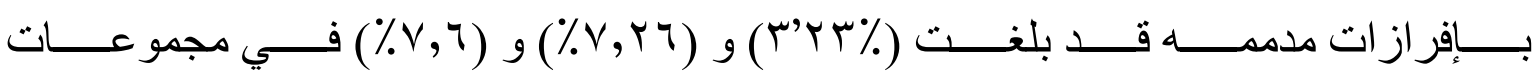

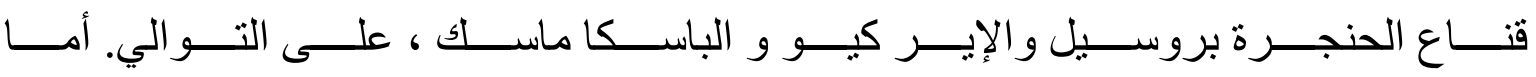

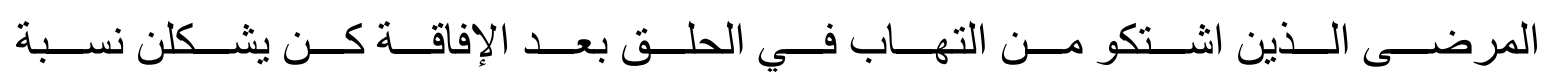




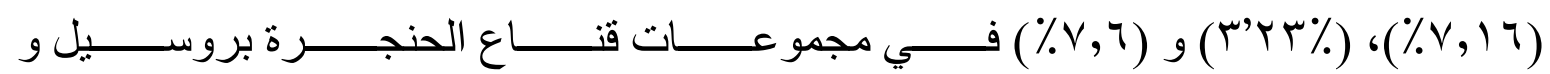

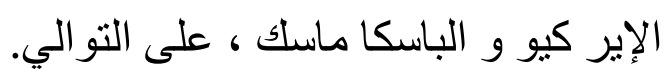

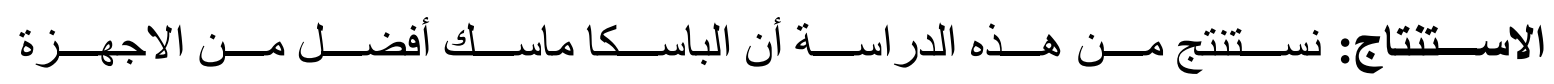

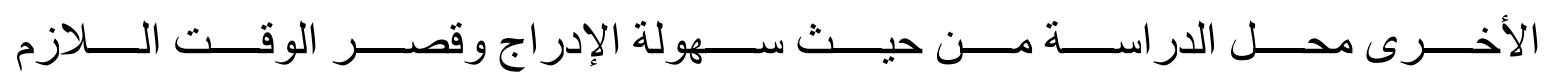

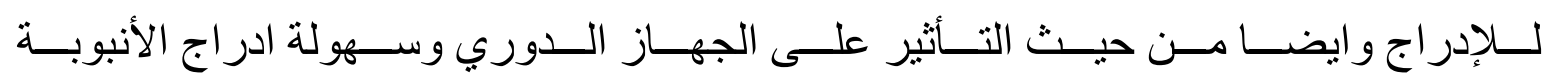

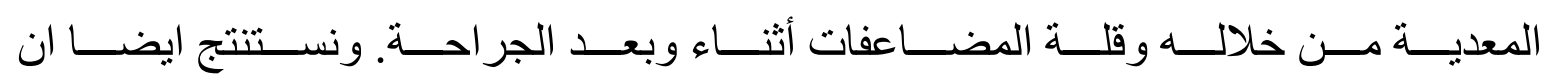

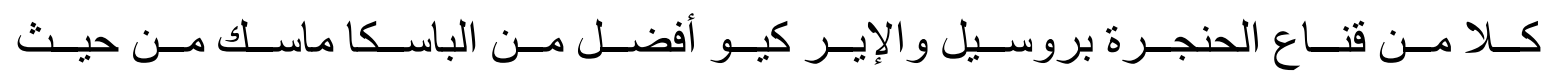

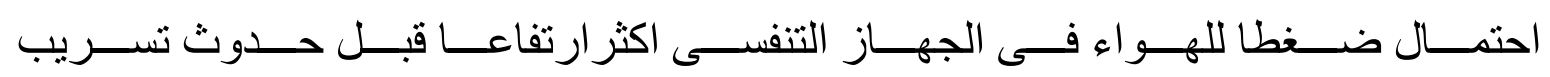

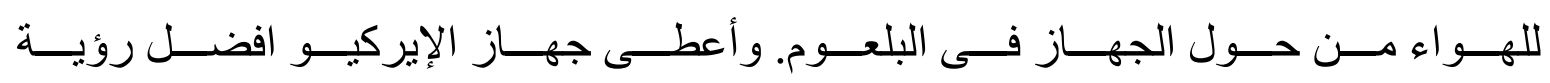

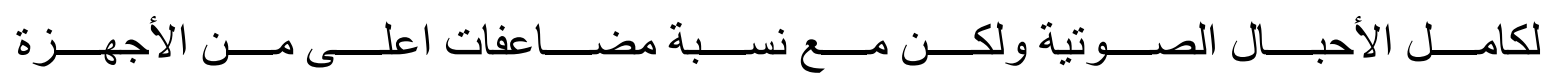

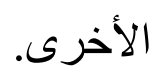

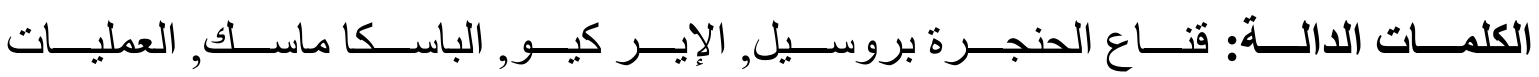
الجر احية. 